\section{Papillary lesions of indolent course: reducing the overdiagnosis of indolent papillary thyroid cancer and unnecessary treatment}

\author{
"No new risk factors, but one, can completely explain the surge of \\ [small papillary cancer] lesions: the exponential increase in the use of \\ diagnostic imaging"
}

\section{Juan P Brito*1, Louise Davies², Claudia Zeballos-Palacios ${ }^{1}$, John C Morris ${ }^{3}$ \& Victor M Montori ${ }^{1}$}

Peter, 43 years of age, presents with an acute exacerbation of chronic neck pain. Peter is on biologicals to treat his inflammatory bowel disease, which triggers an aggressive investigation, including an MRI. This examination was negative except for a $1.5-\mathrm{cm}$ thyroid nodule. A fine-needle biopsy revealed papillary thyroid cancer. After total thyroidectomy that removed the cancer completely, Peter received one dose of radioactive iodine and a prescription for daily levothyroxine to replace his thyroid hormone. Peter is now a cancer survivor.

Worldwide, there is an epidemic of thyroid cancer without a corresponding increase in thyroid cancer deaths [1]. The majority of these cancers are small papillary cancers, the most indolent type of thyroid cancer [2], with a mortality of less than $1 \%$ after 20 years of postsurgical follow-up [3]. No new risk factors, but one, can completely explain the surge of these lesions: the exponential increase in the use of diagnostic imaging.

Similar to Peter, many of us have cancerous lesions in our thyroid glands. The prevalence varies depending on the population studied and the methodology used. Many autopsies in people who died from reasons other than thyroid disease find thyroid cancer. One study suggested that if all thyroid glands were subject to millimeterthick cuts, the pathologist would detect minute or microscopic thyroid cancers in everyone [4].

The biological behavior of this large reservoir of subclinical thyroid cancer is unlikely to have changed over time. What has changed is our ability to detect it through the use of imaging. The correct use of these imaging technologies, for example, neck ultrasonography, has helped clinicians diagnose, treat and follow-up patients with thyroid conditions and has advanced our understanding of those conditions. Its aggressive use, however, has probably led to overdiagnosis of thyroid cancers. Consider the use of neck ultrasonography for the screening of thyroid cancer. Although this practice is not recommended, a recent survey of a random sample of 2000 adult South Koreans who were asked about their

\section{KEYWORDS}

- overdiagnosis • thyroid cancer

'Knowledge \& Evaluation Research Unit, Division of Diabetes, Metabolism \& Nutrition, Mayo Clinic, 200 First Street SW, Rochester, MN 55905, USA

VA Outcomes Group, Department of Veterans Affairs Medical Center, White River Junction, VT, USA

${ }^{3}$ Division of Endocrinology, Diabetes, Metabolism \& Nutrition, Mayo Clinic, 200 First Street SW, Rochester, 
“...we estimate that by the year 2020 the incidence of thyroid cancer in the USA will increase to 23 per 100,000 per year and by 2030 to 31 per 100,000 per year." lifetime screening experience for several cancers revealed that $13 \%$ of them underwent thyroid cancer screening with thyroid ultrasound [5]. In addition, several centers in South Korea conduct screening of thyroid cancer for patients who undergo breast ultrasound for diagnosis and follow-up after breast cancer surgery [6]. This practice might be a contributing factor in South Korea's abrupt increase in incidence of thyroid cancer from 10.6 per 100,000 per year in 1996 to 111.3 per 100,000 per year in 2010 in women; an increase that is unparalleled worldwide [7]. As a result of this practice, thyroid cancer is now the most common cancer in South Korean women.

The location of the thyroid gland, in the lower part of the neck, puts it within the window of many imaging tests. Current ultrasound machines can detect lesions as small as $2 \mathrm{~mm}$. Ultrasound of the neck for parathyroid [8] or carotid conditions (e.g., carotid stenosis) [9] or in otherwise healthy individuals [10] reveals an asymptomatic thyroid nodule in $10-67 \%$ of patients. One out of ten incidentally found nodules harbors thyroid cancer. Thyroid nodules are also easily detected on MRI (hyperintense and hypointense nodules in T2- and T1-weighted images, respectively) and on computerized tomography as the iodine concentration in the thyroid makes these lesions demonstrate high attenuation [11]. The combined analysis of two retrospective studies that examined the prevalence of thyroid lesions in 965 patients undergoing computerized tomography and MRI of the head and neck demonstrated a 16\% frequency of thyroid incidentalomas, with one in ten of these lesions harboring thyroid cancer [11,12]. The incidental discovery of this reservoir has caused the incidence of thyroid cancer in the USA to quadruple in the last four decades: from $3.6 \mathrm{per}$ 100,000 per year in 1973 to 14.6 per 100,000 per year in 2009 [1,101].

Considering the large reservoir of papillary thyroid cancers and the continuous upward trend in the use of imaging, we estimate that by the year 2020 the incidence of thyroid cancer in the USA will increase to 23 per 100,000 per year and by 2030 to 31 per 100,000 per year. However, this may be an underestimate, as it does not take into account the impact of the Affordable Care Act. The Affordable Care Act will expand insurance coverage to individuals regardless of pre-existing conditions. It has been estimated that approximately 30 million more Americans will have health coverage by 2014 [13], many of whom will have imaging studies for the first time, exposing them to the risk of the detection of small papillary thyroid cancers.

Despite the dramatic increase in the incidence of thyroid cancer starting around 1993, over 20 years ago, thyroid cancer mortality over the same period has remained relatively stable and consistent across countries (e.g., USA at 0.5 per 100,000; and South Korea at 0.6 per 100,000) $[2,7]$. Observational studies have strongly suggested that treatment does not change the indolent course of small papillary lesions, which do not evolve to cause metastatic disease or death [14]. Owing to the excellent prognosis associated with small papillary thyroid cancers, it may be reasonable to put them in the same category as has been suggested for ductal carcinoma in situ of the breast [15] - renaming them as papillary lesions of indolent course (PLICs) [16].

Despite their indolent course, experts recommend total thyroidectomy for the treatment of small papillary cancers [17]. This is a costly surgical procedure that requires lifelong thyroid replacement therapy (with its own burden of monitoring and treatment) and puts the patient at risk of complications (surgical hypocalcemia and vocal cord injury) at a rate that varies by surgeon and medical center [18]. Many of these patients also received unwarranted radioactive iodine treatment [19]. Therefore, the overdiagnosis of thyroid lesions leads to their overtreatment.

One approach to curtailing the epidemic of incidentally detected thyroid cancers would be to identify and reduce overtesting, the chief mechanism by which thyroid cancer overdiagnosis occurs. Overtesting is the use of a test unlikely to produce net benefit for the patient. Overtesting encompasses several concepts such as the use of inaccurate tests (i.e., when patients receive a test with poor diagnostic performance) or the use of accurate tests followed by ineffective or imprudent management. In the first case, inaccurate tests misclassify patients. Patients with false-positive results, for instance, receive treatment they do not need and, therefore, are exposed to the treatment's harms and costs without any chance of benefit. In the second case, the case of overdiagnosis, patients are correctly classified (e.g., thyroid nodule harboring papillary lesions) but the ensuing management (i.e., thyroidectomy, long-term thyroid replacement therapy and surveillance for recurrence) is unnecessarily aggressive. The detection and 
treatment of PLICs is, therefore, an example of overtesting and overdiagnosis.

Identification of the types of testing that lead to overdiagnosis may help policymakers develop control measures to reduce the incidence of thyroid cancer. Clinical practice guidelines could prevent overtesting by formulating recommendations against the inappropriate use of tests. Campaigns, such as Choosing Wisely [102] from the American Board of Internal Medicine Foundation, Consumer Reports [103] and other partners, could help disseminate these recommendations to prevent waste and harm. Clinicians can also help prevent overtesting and overdiagnosis by avoiding testing patients in whom outcomes are unlikely to change by knowledge of the test result, a situation that can be detected in clinical trials comparing diagnostic-management strategies.

When an accurate test is used but there is limited confidence in the effectiveness of treatment for those with a positive test and, in the value of reassurance, in those with a negative test, engaging patients in the decision to undergo the test in the first place may be the most appropriate practice. During a shared decision-making interaction, patients and clinicians should discuss potential benefits (e.g., reassurance from a true negative result and access to prompt effective treatment from a true positive) and harms (e.g., false reassurance and delay of effective treatment for those who receive a false-negative result or unnecessary treatment for those who receive a false-positive result and costs and harms from the test and the downstream cascade of tests, incidental findings and treatments). The result of such deliberation should be the selection of management strategies, including the appropriate use of accurate tests followed by effective treatment, that are consistent with the patient's context, values and preferences. Engaging patients at the time of test selection could be an effective approach to reduce the incidence and morbidity of thyroid cancer overdiagnosis and overtreatment.

In conclusion, the incidence of thyroid cancer is increasing worldwide. The majority of small papillary thyroid cancer lesions are found incidentally, often as a consequence of overtesting. Most of these lesions, PLICs, are usually indolent in course and should not be treated aggressively.

We need research to confirm the prognostic information gleaned from extant observational studies and to compare the effectiveness of conservative management strategies and policymaking to curtail overtesting; and to remove the cancer label from indolent lesions, new monitoring and follow-up regimens for patients with PLICs that will succeed in reassuring patients without medicalizing their lives, and patient-centered approaches to care that avoid overdiagnosis and wasteful treatments in people like Peter.

\section{Acknowledgements \\ The authors would like to thank MR Gionfriddo for his valuable comments. \\ Financial \& competing interests disclosure \\ The authors have no relevant affliations or financial involvement with any organization or entity with a finan- cial interest in or financial conflict with the subject matter or materials discussed in the manuscript. This includes employment, consultancies, honoraria, stock ownership or options, expert testimony, grants or patents received or pending, or royalties. \\ No writing assistance was utilized in the production of this manuscript.}

\section{"Engaging patients at the time of test selection could be an effective approach to reduce the incidence and morbidity of thyroid cancer overdiagnosis and overtreatment."}

\section{References}

1 Kilfoy BA, Zheng T, Holford TR et al. International patterns and trends in thyroid cancer incidence, 1973-2002. Cancer Causes Control 20, 525-531 (2009).

2 Davies L, Welch HG. Increasing incidence of thyroid cancer in the United States, 1973-2002. JAMA 295, 2164-2167 (2006).

3 Hay ID, Hutchinson ME, Gonzalez-Losada T et al. Papillary thyroid microcarcinoma: a study of 900 cases observed in a 60-year period. Surgery 144, 980-987; discussion 987-988 (2008).
4 Harach HR, Franssila KO, Wasenius VM. Occult papillary carcinoma of the thyroid. A 'normal' finding in Finland. A systematic autopsy study. Cancer 56, 531-538 (1985).

5 Han MA, Choi KS, Lee HY et al. Current status of thyroid cancer screening in Korea: results from a nationwide interview survey. Asian Pac. J. Cancer Prev. 12, 1657-1663 (2011).

6 Park JS, Oh KK, Kim EK et al. Sonographic detection of thyroid cancer in breast cancer patients. Yonsei Med. J. 48, 63-68 (2007).

7 Kweon SS, Shin MH, Chung IJ, Kim YJ, Choi JS. Thyroid cancer is the most common cancer in women, based on the data from population-based cancer registries, South Korea. Jpn J. Clin. Oncol. 43, 1039-1046 (2013).

8 Stark DD, Clark OH, Gooding GA, Moss AA. High-resolution ultrasonography and computed tomography of thyroid lesions in patients with hyperparathyroidism. Surgery 94, 863-868 (1983).

9 Steele SR, Martin MJ, Mullenix PS, Azarow KS, Andersen CA. The significance of incidental thyroid abnormalities identified during carotid duplex ultrasonography. Arch. Surg. 140, 981-985 (2005). 
10 Guth S, Theune U, Aberle J, Galach A, Bamberger CM. Very high prevalence of thyroid nodules detected by high frequency $(13 \mathrm{MHz})$ ultrasound examination. Eur. J. Clin. Invest. 39, 699-706 (2009).

11 Youserm DM, Huang T, Loevner LA, Langlotz CP. Clinical and economic impact of incidental thyroid lesions found with $\mathrm{CT}$ and MR. AJNR Am. J. Neuroradiol. 18, 1423-1428 (1997).

12 Yoon DY, Chang SK, Choi CS et al. The prevalence and significance of incidental thyroid nodules identified on computed tomography. J. Comput. Assist. Tomogr. 32, 810-815 (2008).

13 Obama B. Securing the future of American health care. N. Engl. J. Med. 367, 1377-1381 (2012).

14 Ito $\mathrm{Y}$, Miyauchi A, Inoue $\mathrm{H}$ et al. An observational trial for papillary thyroid microcarcinoma in Japanese patients. World J. Surg. 34, 28-35 (2010).

15 Omer ZB, Hwang ES, Esserman LJ, Howe $\mathrm{R}$, Ozanne EM. Impact of ductal carcinoma in situ terminology on patient treatment preferences. JAMA Intern. Med. 173(19), 1830-1831 (2013).

16 Brito JP, Morris JC, Montori VM. Thyroid cancer: zealous imaging has increased detection and treatment of low risk tumours. BMJ 347, f4706 (2013).

17 Cooper DS, Doherty GM, Haugen BR et al. Revised American Thyroid Association management guidelines for patients with thyroid nodules and differentiated thyroid cancer. Thyroid 19, 1167-1214 (2009).

18 Giordano D, Valcavi R, Thompson GB et al. Complications of central neck dissection in patients with papillary thyroid carcinoma: results of a study on 1087 patients and review of the literature. Thyroid 22, 911-917 (2012).

19 Iyer NG, Morris LG, Tuttle RM, Shaha AR, Ganly I. Rising incidence of second cancers in patients with low-risk (T1N0) thyroid cancer who receive radioactive iodine therapy. Cancer 117, 4439-4446 (2011).

\section{- Websites}

101 Howlader N, Noone AM, Krapcho M et al. SEER Cancer Statistics Review, 1975-2009, National Cancer Institute, MD, USA. http://seer.cancer.gov/csr/1975_2009_ pops09/

102 Choosing Wisely. www.choosingwisely.org

103 ConsumerReports.org www.consumerreports.org 